\title{
Decision Support Systems: Structural, conversational and emotional adjustments: Breaking and taking of organisational care
}

\author{
O. García and R. Orellana \\ CIGAR Ltda. \\ Padre Mariano $N^{\circ} 103$, Of. 602 \\ Providencia, Chile. \\ Tel +52 $23660172 / 3660173 \mathrm{Fax}+5222355383$
}

\begin{abstract}
Computer and communication technology has been used extensively in organisations to enhance the management process but experts and users report dissatisfaction with the design process and the support provided by technological systems. Increasing their effectiveness is not a question of more or better technology but one of re-interpretation of action and the manager's activity. According to developments in cognitive biology, human beings do not act based on a representation of the world and this contradicts the current foundation of the concern for providing information as an accurate representation of relevant reality. Therefore human understanding as an observer in language opens a new perspective of management. Language as the recursive flow of consensual coordinations of behaviour that constitutes a manner of living together, allows for the generation of the complexities that managers must cope with to take care of the viability of the Human Activity Systems under their responsibility. This continuous criss-crossing of consensual coordinations of consensual coordinations of behaviour follows the changing complexities of living together in a changing world; learning and acquiring new and more powerful languages to observe and coordinate in the domains of action that characterize the identity of the Human Activity System is a practice concerning viability. We understand conversation as the braiding between language and emotions, but emotions are changed in language, changing the disposition for action. Computer and communication technology can be reinterpreted as a conversational device that triggers the language and emotional processes of the community sharing the concerns of the manager.
\end{abstract}

\section{Keywords}

Taking care, human activity system, language and emotions, observational language, organisational learning. 


\section{INTRODUCTION}

The main purpose of this paper is to contribute to the discussion about the design of computer and communication systems that can aid the management process.

\subsection{Historical Overview}

We propose that Decision Support System can be considered as a design conception conceived within the computer industry to facilitate the use of computer technology in organisations (Keen, 1991). This framework, built during the late 1970s, offers computer and communication technology as support to the decision process which constitutes, in this view, the core of the management process. The DSS framework offers the following capabilities:

- Access : ease of use, wide variety of data, analysis and modelling capacity.

- Technological : software generation tools.

- Development modes: interactive and evolutionary.

Within this perspective, computer and communication technologies are seen as an amplification of the human data processing capabilities which limit the decision process. Thus, the human being is understood metaphorically as a data processing machine. Mental processes are associated with the manipulation of symbols and human communication to signal transmission.

The decision taking process a la 1970s is based upon the assumption that there is an objective reality, independent of the human being, that is coping with organisational performance. Thus, the manager requires an accurate representation of relevant aspects of reality through data and therefore the decision taker (manager) must have the capacity to identify problem situations and define alternative courses of action. Criteria must be selected so that the alternatives can be compared under a common rule which specifies the "best alternative" to be chosen.

The recognition that it is not always possible to follow this process has originated the term "unstructured decisions": the higher the managerial level the more unstructured the decision process becomes. Flexibility in the manipulation of data, ease in the construction of models, and group participation in the resolution process have been some of the answers to the dilemma.

Within this DSS framework, "supporting the manager" means to provide a wide variety of data, to be analysed and modelled in various ways, in a friendly environment which allows for the effective use of the technological tools offered (Fick and Sprague, 1980). All this should lead to an increase in the manager's capacity to take action.

Today this view is regarded by several authors as a mistaken oversimplification of what is involved in taking action. The history of the practice of design and implementation of computer systems has shown that the assumptions regarding the management process do not always sustain an effective design and implementation 
process. This situation offers an opportunity to review the design assumptions of DSS.

Criticism and dissatisfaction regarding the use of computer and communications technology in the managerial process has been reported throughout the years. This situation is consistent with a community engaged in a permanent learning process. The understanding of the decision process leads to the belief that it is possible to obtain an accurate representation of reality. Signs of this is not the case are the unfulfilled promises of Operations Research about the role of mathematical models in management, and those of Artificial Intelligence, indicating the limitations of representing the underlying "cultural knowledge" present in the practices and traditions of a community.

The assumption that managers take correct decisions, based on accurate information, has lead to the belief that managers knew what information they needed, that "good" information produces "good" decisions, and that the information needed was independent of the manager (Schlumberger, 1997). In practice, this has not been found to be the case. As a result, the role of the traditional system designer or analyst, and the difficulties and limitations it entails, have been reexamined, establishing that the assumptions of an objective observer of the managerial reality must be very well qualified and that his or her role should be redefined (De Zeeuw, 1993, Humphreys and Berkeley, 1995).

Furthermore, it has also been argued that the computer and communications systems (EIS, DSS, expert systems...) will be only as good as the management processes they support. The argument implies that, to a large degree, the individual competencies of managers, are secondary to the quality of the organisational conversations underpinning their decisions.

Certainly there has been some response to this dissatisfaction. The concern for proper support for the manager has led to an effort to include the concern for human capabilities into the design process. Attempts have been made to include cognitive styles, abstraction levels, processing capacities, and ergonomic considerations, in various ways, in an attempt to improve the use of technology in organisations. Nevertheless this effort has not been fully successful and has not yet permitted a breakthrough in the full use of technology in the management process.

We would put forward the proposition that what has been lacking is an appropriate understanding of the management process, particularly regarding the structural capacities of human beings, who have the capacity of language and emotion as the grounds for action. In the following, we will attempt to present the possibilities that stem from a reinterpretation of the management process focused on the human being responsible for "taking care" of the organisation. 


\section{THE MANAGER REVISITED}

Our starting point is to begin to question our understanding of the human being and his capacity to act, which is included in the work of Humberto Maturana (1969, 1978, 1994, Maturana and Varela, 1984) on the biology of cognition. We will summarily show what we consider the most important conclusions regarding the manager and his capacity to cope with the wide variety of situations relevant to "taking care" of the organisation.

Maturana establishes that the human being, as a living system, is determined by the structure of his nervous system. The conclusions following this statement are many:; one of them is that living beings do not perceive an objective reality. What ever we perceive is determined by our nervous system. Given the plasticity of our nervous system, this means that what we observe in a given situation is filtered by our education and experience: a situation is not perceived in the same way by a lawyer and an engineer. The set of distinctions characterised by the specific training received will be revealed by what is perceived by either of them and that this has as a direct consequence in our understanding of information. In our interpretation of what Maturana is saying, this means that information can be reinterpreted as a trigger of a the nervous system.

What triggers a particular observer into action may not be noticed by another, so that this situation will generate different behaviour by different human beings, given the fact that they have different historical paths. This is in direct contradiction with the pretence that underlies the design of information systems: the representation of an objective reality. A second conclusion is that there are domains of action in which they have no distinctions and therefore they are not able to observe action. This becomes transparent as we reflect upon our learning process as once we have learned something fresh we can observe situations we did not observe.

In Maturana's view, language shows up in human interaction, shows up among living beings as a flow of consensual coordinations of consensual coordinations of behaviour. Words appear, not as names given to objects, but as the possibility for consensual coordination of behaviour. An apple is not necessarily a description of an object but indicates the possibility of eating or baking a pie.

A human being, constitutively blind, must cope with the complexities of living by coupling with other human beings through language constituting a conversational network. By coupling in language, the nervous system is triggered, changing the disposition to act. Transformations in the dispositions to act is what we characterize as an emotional state.

Here we state a design consideration: the manager, blind and ignorant, lives in a continuous criss-crossing of language that gives rise to complexity. He copes through a conversational and emotional network of support. Within this 
configuration, technology can be understood as the possibility of strengthening his capacity of observation and enhancing the triggering of emotion and action.

In the understanding of the designer, the rational decision maker must be replaced by a new type of manager, emotional and limited, who despite his apparent ignorance and blindness caused by historical traditions to which he belongs is capable of observing, learning and constituting worlds in language and taking care of them.

Taking care of organisations in the midst of changing conditions is the concern of managers. We are saying that any enhancement in the design considerations of technological support for managers must be structured upon the understanding of the manager as a human being. We stress the point that we have enough technological power, we have enough "raw computer mips", "gigabytes of storage", and related indexes and pointers, to build useful and effective devices. What is lacking is a more powerful understanding of the management process generally by all concerned (Humphreys, Berkeley and Jovchelovich, 1996).

\subsection{Emotions and Action}

In concerning ourselves with the design of management support tools, we expect to create organisational mechanisms that support the manager in his resolution process towards committing himself and others to action. We are attempting to enhance the manager's capacity to initiate action at ground level (Argyris and Schon, 1978).

The concern for action is the concern for peoples' emotions, for provoking a transformation in the disposition to act. It is part of our daily experience that changes in emotions result in changes in our disposition to act. Nevertheless, emotions is not a subject that is often related to management except as a background for action. Such is the sense that words like "organisational climate" or "motivation" convey. From the perspective of action we are not concerned with the background mood but with focusing on a problem situation. Words such as important, urgent, threatening, opportunity or irrelevant show different dispositions to act.

DSS can be conceived then as the capacity to trigger these different states. In the extreme it can be understood as producing calm or alert states. In this sense we can say that DSS must be conceived with the perspective of opening and closing emotions.

The above does not mean that rationality has no place in our understanding of action. Action is the outcome of the braiding of language and emotion. Conversations are moments in which emotions can be changed so that action is possible. The appropriate mix of emotions and conversations makes management possible Garcia and Alvarez, 1991). From this perspective we can say that DSS can be conceived as a conversation triggering machine.

The design of an appropriate network of conversations must be tuned to the manager. The concern for his or her own stability, and the stability of the system 
under his or her care, is the basis for establishing what kind of conversations and which participants should be involved in the resolution process regarding a category of problem situations. From this perspective, Decision Support Systems can be understood as a subset of a family of tools designed to trigger conversations and emotions for action in the domains of concern of the manager's stability.

\subsection{The Manager in the Human Activity System (HAS) or the Organizational Observer}

In the domain of organizational design, of which the concern for design and implementation of DSS should be understood as a subset, the grounding for any action is distinguishing and naming a human activity system (Checkland, 1981; Checkland and Scholes, 1950). That a system is a distinction made by an observer is a fundamental fact for organizational design and intervention. Therefore, it is to our benefit as designers of technological interventions in organizations to understand what is going on as a social process when someone says "I take care of this organisation."

What are we distinguishing when we distinguish an organization? When we make the operation of distinction we bring forth a class identity. We may say that the specific human activity system under our care is a school, a distribution network, or an army. By distinguishing it as such, we are saying that it belongs to the class of organizations in which certain relations are present among the people that participate in it. This characteristic relational network of conversations and emotions is the system's organization.

The structure of the system is the specific form in which the relations exist in each case (Ashby, 1977). We may have different structures that conform to the same organization, i.e., that belong to the same class identity. When making the distinction system, we distinguish those elements that are part of the system and those that are excluded from the system and constitute the environment.

It is important for effective design to notice that two or more different observers may distinguish different organizations (Humphreys and Berkeley, 1995). The manager, the lawyer, and the engineer may use the same name "the company" and imply very different situations. For a company raider, the human activity system may be a device to generate financial flow, to its manager it may be a group of people committed to produce satisfaction to clients and to the head of the union it may be a device for the generation of dignified working conditions.

But we are not submerged in the midst of unmanageable chaos: it is important to remember that people belong to communities that have a common history and tradition and that have been coupled together in their interactions to each other (Beer, 1979). As a result of this there are shared distinctions and blindness through joint experience. becomes clear when we compare the engineer's and psychologist's views of the world.

This is a sensitive issue for an organizational intervention. We can ask then, from the perspective of design of technological interventions in an organization, 
- what type of observer is the manager;

- how computer and communication systems enhances the manager's capacity to observe the system and its environment;

- how it generates conditions for collaboration with other observers in taking care of the performance of the organization; and

- how it helps to reveal blindness that characterize the community and threatens the organisation's viability.

If there is a language of distinctions, interests, and values concerned with the viability of the organization that can be triggered by using technology, in conditions of mutual respect and learning, then we have improved the capacity for action and care.

\section{THE NEED FOR AN ORGANIZATIONAL FRAMEWORK IN THE DESIGN OF COMPUTER TECHNOLOGY SYSTEMS}

Our exposure to the complexity of the world is increasing. There is no place to hide from the economic, technical, political, and cultural influences (Batten, 1973). Our "neighbours", people that have a daily impact in our lives, may be hidden from our view not only by geographic distance but also by "systemic distance": they may participate in other industries, they may pertain to a political party, they may be arranging some economic agreement or inventing some technological device.

From the organizational perspective, this situation is lived as a loss of stability: the future can no longer be a repetition of the past. New problem situations arise for management, flexibility to adjust, learning capacity and the will to adapt appear as a "need" for maintaining the organisation's identity (Beer, 1985).

Managers need help as the task of managing under these conditions is taking its toll. Very long hours, strained backs, insomnia, stress, drug abuse, and broken families are reported by people in management positions. This pain, or its anticipation, is the starting point for a meaningful organizational intervention: we must be able to provide a response to a situation of unbalance between human capacities and the complexity of the world. This unbalance is the main concern for design of organizational structures of which technology is one of the pillars. Thus, it is necessary to develop a DSS framework including a new understanding of the manager and the managing process.

\subsection{Observing Organisations}

The concern for the creation of distinctions by which to observe organizations is related to the need for an enhanced capacity to design tools and mechanisms for 
managers to deal with the complex task of taking care of the organisation's viability.

The design and implementation of the capacity to modify the context in which people work in an organization is enhanced by a set of distinctions that are the tools for observation and reflection. This process will bring changes in the identity of the firm, in its vision of the future, and in its interpretation of performance and viability, generating new conversations for commitment and action.

Some of the basic distinctions to observe in organisations, are the following:

- Identity: the process of organizational self reflection allows for the rising of questions in which people can examine the meaning of their work as an enhancement of the organisation's viability. The understanding of work in the light of the whole allows for discussion about the balance between organizational policies and decision taking.

- Distributed management: as managers take care of multiple domains of action, networks of trust can be established to absorb the variety of contingent situations, the design of the networks involves the specific distribution of responsibilities to take care of complexity (Espejo and Garcia, 1984).

- Complexity unfolding: the understanding of viability allows for the proposition of a recursive structure of care that specifies domains of action that constitute the identity. This is the basic care structure.

- Functional capacity unbalances: the concern for the gap between what is being done and what is possible reveals functional capacity unbalances regarding structure, the conversational network and technological support.

- Organizational Learning Inhibitors, establishing conditions for organizational learning requires building up the organisation's self reference capacity which could be triggered by the adequate design of conversational support based on computers. The design should consider "cultural" as well as technological inhibitors.

- A distinction as an observational device: The design of DSS requires analysts who are capable of observing the human activity system from an organisational perspective, that is, starting from the concern for its viability (De Zeeuw, 1992; De Zeeuw and Schuurman, 1997).

\subsection{Organizational Learning and Viability}

Taking care of the organisation's viability under conditions of continuous change and increasing complexity requires the development of the organisation's learning 
capacity. It is not simple or easy to generate new behaviour. There is abundant evidence to quite the contrary, even in circumstances when viability has been at stake. Thus, in the present state of affairs, more that ever the organisation's viability is mediated by its learning capacity.

Our challenge is to increase the structure's plasticity, that is, to increase the possibility of new behaviour. We are not referring here to some abstract process: learning always implies a human involvement.

The organizational structure can be characterised from the perspective of its capacity to inhibit learning. The lack of conversations about what people do, the social impossibility for a beginner to ask for explanations, the understanding of the good professional as someone that does not commit mistakes, and excessive inbreeding are some of the organizational habits that we all notice.

The design of computer and communication support for management must include the concern for the learning process. This is a matter of organizational mechanisms capable of generating conditions for people to observe their own behaviour, as it relates to the system's viability and the emotional environment for changing it, accepting ignorance, blindness and mistakes.

\subsection{Organisational Transformation}

An organisational transformation is a managerial action to cope with the regulatory unbalances between his functional capacity and perceived complexity. To detect unbalances and to manage the required change process, the manager must characterize action and learning in the following domains:

- structural adjustment of the organization, which implies changes to the organisational identity, functional capacity, learning and adaptation mechanisms in order to absorb the complexity at different recursive levels within the contexts and domains to which an observer (the manager) is coupled.

- adjustment to the bodies, language, emotions, conversations that constitute the organisational network. This is the network of trust, collaboration, and solidarity. This domain shows up as the competence to listen, to speak, and to interpret.

These are the domains for action in which DSS must play a role.

\subsection{The Metasystemic Perspective}

The manager must not only observe the system under his care, he must also observe other Human Activity Systems in which it is embedded such as markets, government, industry, and technology. This is the metasystemic scenario. 
To take care of the organisation, management must be aware and assesses the actions taken in the embedding systems (changes in the tax structure, new technologies, changes in the cost structure of the industry) or other systems that share its identity. and also generate interpretations about its future behaviour and its impact on viability (Garcia, 1989).

This capacity may be enhanced by technological support that combines the observation of domains related to the organisation's stability with the interpretation capacity of a network of experts. This network and the shifts it produces in the interpretation of what is relevant for the industry may also shift the stability criteria of managers.

New possibilities for action are made possible by the transformation of the interpretation that managers have about their environment. An opportunity for the redesign of the DSS framework also lies in the requirements for an effective navigation in the metasystemic spaces that are related to the taking care of organisational viability.

\section{OUR PROPOSITIONS FOR DESIGNING AND USING DSS}

To enhance the possibilities of the design of DSS it is necessary to shift the observer of computer and communication technology from its closure in the domain of signal and symbol manipulation to the domain of organisational transformation.

We propose that technology, in the context of organisational transformation, must be understood within the following context:

- As a functional capacity to regulate the balance between a human being and the Human Activity System under his care.

- To maintain the regulatory balance which implies the dynamic adjustment of the braiding of emotions and language that constitutes the Human Activity System.

- To design technology in the domain of organisational transformation is to create coupling conditions between the manager and the Human Activity Structure allowing for their mutual transformation

Mechanisms conceived from the perspective of an organisational transformation technology trigger conversations and emotions in the network of relations that constitute the organisation to take action in order to adjust the organisational structure, to modify the relational configuration and the use of technological support. Some of the contributions of devices of this sort could be:

- Enhancement of managerial capacity to observe the organisational activity and anticipate problem situations. In this framework the DSS should provide a 
capacity to measure activities that constitute the organisational identity according to the manager's concern for stability.

- Enhancement of the capacity to filter the variety that characterises organisational and environmental activity.

- Support to permanently assess the network of trust observing the state of mutual promises.

- Dynamic articulation of conversational networks of care according to problem situations.

- Triggering of conversations regarding the stability of the Human Activity System.

Amplification of the managerial capacity to reach out to different and distant networks that the manager relates to his own and organisational stability.

\section{FINAL REMARKS}

Managers need support to cope with the increasing rate of change of systemic and metasystemic conditions. Coping requires organisational transformations or adjustments. In order to enhance decision support systems, we think that research programs in the following areas may provide with a stronger language for design of DSS:

- The further development of distinctions and practices regarding the management of organisational transformation. The introduction of computer and communication technology changes the balances between people within the human activity system.

- The development of practices to enhance, trigger and regulate conversations associated to taking care of viability. Further work needs to be done regarding the conversations that constitute the observers of viability.

- The development of an educational capacity to show the impact of cognitive and cultural blindness regarding language, action and emotions would allow for the generation of new competencies in managers and analysts regarding the taking care of organisations and people.

- The inhibiting of learning in organisations. The role of technology in triggering learning situations and modifying structural inhibitions. 
- The role of trust, and the generation of networks of trust, as enhancement of the manager's capacity to design organisational structures from the perspective of observing, learning and action.

- The conceptualisation of conversational filters and amplifiers to deal with complexity.

Research oriented towards these topics may help to deal with the dissatisfaction of different participants in the drama of organisational transformation. We are concerned with the dissatisfaction that we see in managers:

- There seems to be no adequate education for managers regarding design and management of organizational processes: managers must deal with organizational adjustments from their understanding of managing the business.

- There is an apparently low rate of success in organizational interventions that deal with what we may call the soft aspects of the organization such as learning, autonomy, identity, conversational networks and the emotional upheavals that are part of organizational adjustments.

We are concerned with the dissatisfaction that we see in consultants:

- Consultants have developed a strong understanding of specific, specialised and well defined interventions but this is no longer a strong base for business: today's client's interest is not only technology or procedures but in a reinterpretation of their business that takes hold in their people.

- Normally consultants have no theory which allows them to be a strong partner of their client $\mathrm{s}$, as they almost never work for the people who are actually in the jam of managing organizational viability and stability.

We are concerned with the dissatisfaction of professors and students:

- The present scientific approach to management appears to have failed: mathematical models operational research techniques have been recognised as able to deal with problem situations of very limited complexity and do not deal with human nature.

- Even though this has been recognised painfully by students who emerge into practical life, it is not fully recognised inside the ivory towers of institutional knowledge. 
- Business schools that, theoretically, are preparing students to be managers have a technical, professional perspective that does not include an understanding of the human activity systems within which the professional activities take place.

- Organization is not understood as something that happens in the interpretation of people, and tends to be treated as an object which can be systematically analysed without reference to the different observers of activity (Habermas, 1992).

Our concern in writing this paper has been to make a contribution of use to the people concerned with effective organizational interventions and also to participate in the development of organizational theory, which we think is still in its early stages of development.

\section{REFERENCES}

Argyris, C. and Schon, D. (1978) Organizational Learning: A Theory of Action Perspective. Addison-Wesley.

Ashby, R. (1977) Introducción a la Cibernética". Nueva Visión, Buenos Aires. Bateson, G. (1973) Steps to an Ecology of Mind. Paladin, St. Albans.

Beer, S. (1979) The Heart of Enterprise. John Wiley \& Sons, New York..

Beer, S. (1985) Diagnosing the System for Organizations. John Wiley \& Sons. Chichester.

Checkland, P. (1981) Systems Thinking, Systems Practice". Chichester, Wiley. Checkland, Peter and Scholes, J. (1990) Soft Systems Methodology in Action Wiley, Chichester:

Davenport, T. (1992) Process Innovation. Reeingineering Work Through Information Technology. Harvard Business School Press, Cambridge, Mass.

Espejo, R. and García, O. (1984) A Tool for Distributed Planning. Baden Baden, Germany

Espejo, R. (1993) Strategy, Structure and Information Management. Aston Business School, Manchester, U.K.

Fick, G. \& Sprague, R. (1980) Decision Support Systems: Issues and Challenges". Pergamon Press, Oxford.

García, O. (1989) Sobre el Diseño de Reingeniería Humana para la Acción". Documento de Trabajo del Proyecto de Investigación "CYBERCOM II: Rendimiento y Conversaciones en un Contexto de Efectividad Organizacional. Santiago, Chile

García, O. and Alvarez, J. (1991) Las Ontologías Cibernética y Conversacional: Un Examen Crítico. Instituto Andino de Sistemas, Lima, Perú. 
Habermas, J. (1992) The Philosophical Discourse of Modernity". Cambridge, Polity Press.

Humphreys, P. and Berkeley, D, (1995) Organisational process modelling sensitive to local social and cultural conditions, in Work and organisational psychology: European contributions of the nineties (eds J. M. Piero, F. Prieto, J. L. Melia and O. Luque). Erlbaum/Taylor and Francis, Hove, U.K.

Humphreys, P.C., Berkeley, D. and Jovchelovitch, S. (1996) Organisational psychology and psychologists in organisations: Focus on organisational transformation. Interamerican journal of psychology, 30, 27-42.

Keen, P. (1991) Shaping the Future: Business Design Through Information Technology". Harvard Business School Press, Cambridge, Mass.

Maturana, H. (1969) Cognition a Multiple View. Spartan Books, New York.

Maturana, H. (1978) Psychology and Biology on Language and Thought. Academic Press, New York.

Maturana, H. (1993) Desde la Biología a la Psicología. Editorial Synthesis, Santiago, Chile.

Maturana, H. (1994) Autopoiesis: la Organización de lo Vivo. Santiago, Chile.

Maturana, H. and Varela, F. (1984) El Arbol del Conocimiento. Editorial Universitaria, Santiago, Chile

Schlumberger, M. (1997) When wrong is right. This volume

Varela, F., Thompson, E. and Rosch, E. (1992) The Embodied Mind: Cognitive Science and Human Experience. Ed. Gedisa, Santiago, Chile

De Zeeuw, G. (1992) Competence and the Observational Language. Centre for Innovation and Cooperative Technology, University of Amsterdam, Netherlands .

De Zeeuw, G. 1993) Soft Knowledge Accumulation and the Rise of Competence". Systems Practice, 5, 192-215.

De Zeeuw, G. and Schuurman, J. G. (1997) Support as intervention in decision processes. This volume.

\section{BIOGRAPHIES}

Osvaldo Garcia de la Cerda is a professor at the Industrial Engineering Department of the University of Santiago de Chile. His current research is on human reengineering for action and on metasystemic design. He is the managing director of CIGAR Ltda., a management consultancy in the field of organization transformation.

Renato Orellana Muerman is civil engineer, graduate of the University of Chile. He has more than 20 years of experience in the field of organizational transformation and is a senior consultant with CIGAR Ltda. 